socio-political issue among empowered Filipino TG women. Recognizing similar sexual behaviour risks among MSM and TG women, the latter associated with body modifications concept(i.e. hormone replacement, collagen injections/implants) have a heightened risk due to unsafe and improper injecting practises. Thus, the ISEANHivos Program (IHP) (a Global Fund Multi-country Grant) in the Philippines, through consultations with the TG community, aims to develop an operational TG definition that would hopefully be feasible in a national surveillance.

The method used was the conduct of four (4) focus group discussions (FGDs) with TG women members (with 5-10 participants each FGD) from community-based organisations (CBOs) in Metro Manila, Cebu City and Davao City.

The findings revealed that majority of the participants do not generally agree with the three (3) proposed qualifiers/criteria in identifying TG women used in the IHBSS 2011 MSM questionnaire. "Looks like a female" is subjective; "Taking/injecting hormones" is not necessary; and those who have "undergone sex reassignment surgery" would identify themselves as a non-TG woman. Some of the suggestions are the inclusion of a time element in one's gender identification/expression to eliminate those who just occasionally identifies/express themselves as female; consider any form of affirming one's identity as a woman; and the use of three (3) questions - asking one's sex assigned birth, gender identity and gender expression.

The study concludes with IHP-Philippines' proposed operational definition of TG women: those whose sex assigned birth is male; and whose gender identity is generally female and/or whose gender expression is generally feminine. They need not undergo any form of body modification, may have varying sexual orientations, and may self-identify using various local gender terms.

\section{P3.437 HARVAT: SEX WORK INVOLVEMENT AND ASSOCIATED OCCUPATIONAL RISKS AMONG SELECTED TRANSGENDER WOMEN IN CEBU CITY, PHILIPPINES}

doi:10.1136/sextrans-2013-051184.0887

R N Cortes. Philippine NGO Council on Population, Health and Welfare, Inc., Pasay City, Philippines

The expansion of sex work (or harvat in Cebu) in the Philippines has surfaced transgender (TG) escorts and online-based sex workers (SWs), who are generally exposed to health risks such as sexually transmitted infections (STIs), HIV/AIDS. Recent Philippine Integrated HIV Behavioral and Serological Surveillance (IHBSS) 2011 showed Cebu City having the second highest HIV prevalence among men who have sex with men (MSM) (i.e. 4.7 percent); which TG women are included. Due to the lack of social recognition of TG women, combined with the stigmatisation of SWs, this leads to discrimination, violence and health risks among TG women SWs. Hence, it is important to look at their gender identity and selfdescription; context and nature of sex work involvement; and their perceived/experienced occupational risks.

The method used was face-to-face in-depth interviews with fifteen (15) TG women SWs in Cebu City as identified by the researcher. Content analysis was used for qualitative analysis of transcribed interviews. The findings revealed that TG women SWs do not necessarily identify themselves as TG but see themselves as women expressed in different modalities, but commonly undergoing body modifications (i.e. hormone pills, collagen injections). Economic benefits and sexual enjoyment gained are the main motivations for TG women SWs, which is related to greater preference for foreigner clients and "versatile" sexual role. Escorting has the most economic benefits, followed by online chatting and online harvat. Lastly, there were lesser experiences of occupational risks (i.e. health, abuse, legal) than what they perceived.
The study concludes that perceived/experienced risks associated with sex work are not merely occupational, but are also behavioural and gender-based. As such, sexual behaviour and not their occupation as SWs make TG women at risk to STIs, HIV/AIDS. Hence, HIV education and prevention strategies should be client-specific to address health needs of the general TG women population.

\section{P3.438 CHALLENGES IN MANAGING TRANSGENDER INDIVIDUALS - OBSERVATIONS IN A UK SEXUAL HEALTH CLINIC}

doi:10.1136/sextrans-2013-051184.0888

H Roberts, K A Fernando, H Jaleel. Southend University Hospital NHS Foundation Trust, Essex, UK

Background Transgender individuals may have complex medical and psychosocial needs. Prior studies have reported an increased incidence of STIs including HIV. Low self esteem, social isolation, self-harm and suicide have been observed with greater frequency. Additionally, a greater likelihood of being subject to relationship violence and sexual assault is recognised. Discrimination in school or the work-place, and even in healthcare settings adds to psychological burden. Healthcare seeking behaviour of transgender individuals may, therefore, be adversely affected.

Cases: We share experiences of two transgender patients and their health concerns.

The first underwent gender reassignment 20 years ago (aged 19) She reported psychological problems including depression, anxiety attacks and a prior suicide attempt. In 2010 she was diagnosed with HIV when presented with pneumocystis jirovecii pneumonia. Antiretroviral therapy (ART) management has been challenging with regards to exacerbation of psychological ill-health thought due to the ART agent, efavirenz. This was, therefore, substituted with rilpivirine, with favourable outcome. Reluctance to disclose her HIV status to her partner persists. Additionally, self-purchased 'hormonal' medication remains concerning with regards to unsupervised use and potential ART interactions.

The second patient underwent gender reassignment 15 years ago. She is HIV negative and presents with unusually frequent recurrences of anogenital warts, bacterial abscesses and herpetic ulcers. She also has a psychosexual disorder thought resulting from prior sexual abuse

Discussion Concern remains regarding lack of awareness amongst health care professionals (HCPs) with regards to the above complexities and the need for appropriate, empathic and non-judgemental management. Surveys of medical school curricula highlight that transgender health needs are often omitted, with limited professional information resources.

Conclusion HCPs must remain aware of the increased risk of mental and sexual ill-health. This will allow timely recognition of such problems and prompt intervention. Intervention may require collaborative interagency approaches with HCPs from mental health services.

\section{P3.439 UNDERSTANDING THE LOCALISED PERSPECTIVE ON TRANSGENDER WOMEN FOR DEVELOPING TRANSGENDER- SPECIFIC HEALTH SERVICES AND HIV PREVENTION PROGRAMMES IN THE PHILIPPINES}

doi:10.1136/sextrans-2013-051184.0889

R N Cortes. Philippine NGO Council on Population, Health and Welfare, Inc., Pasay City, Philippines

The Philippines do not have localised term to refer to transgender (TG) persons. In fact, the common local terms "bakla", "bading" and "bayot" are negatively used to refer to TG women. Even the Philippine Integrated HIV Behavioral and Serological Surveillance (IHBSS) do not disaggregate data for men having sex with men (MSM) and 